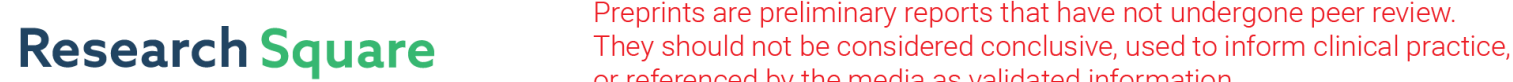 or referenced by the media as validated information. \\ RNA sequencing reveals BMP4 as a basis for the dual-target treatment of diabetic retinopathy
}

\section{Lijie Dong}

Tianjin Medical University Eye Hospital

\section{Zhe Zhang}

Tianjin Medical University Eye Hospital

\section{Xun Liu}

Tianjin Medical University Eye Hospital

\section{Qiong Wang}

Tianjin Medical University Eye Hospital

\section{Yaru Hong}

Tianjin Medical University Eye Hospital

Juping Liu ( $\nabla$ cythnia951120@126.com )

https://orcid.org/0000-0001-9720-8227

\section{Xiaorong Li}

Tianjin Medical University Eye Hospital

\section{Research}

Keywords: Diabetic retinopathy, RNA sequencing technology, High glucose, BMP4, dual-target treatment

Posted Date: March 18th, 2020

DOI: https://doi.org/10.21203/rs.3.rs-17616/v1

License: (c) (i) This work is licensed under a Creative Commons Attribution 4.0 International License.

Read Full License 


\section{Abstract}

Backgroud: Diabetic retinopathy, currently considered a neurovascular disease, has become the major cause of blindness. Continuously high glucose levels are regarded as a risk factor for DR. Intravitreal injection of anti-VEGF drugs is a classic treatment for DR; however, anti-VEGF drugs can exacerbate fibrosis and eventually lead to retinal detachment.

Methods: We explored changes in gene expression in high-glucose-induced vascular endothelial cells using RNA sequencing technology, utilized transcriptome signatures to explore the pathogenesis of DR and identified new treatments that can provide dual-target intervention for angiogenesis and fibrosis. We identified BMP4 and SMAD9 among 449 differentially expressed genes from RNA-seq data and investigated the expression of these two genes in the blood of diabetes patients and in STZ-induced rat retinas. Moreover, considering that DR is a multifactorial and multicellular disease, we used $\mathrm{H} 2 \mathrm{O} 2$, AGEs, $\mathrm{CoCl} 2,4 \mathrm{HNE}$ and hypoxia to induce three human retinal cell types (Müller, RPE and HRCECs) to simulate the pathogenesis of DR and then verified the overexpression of these two genes in the cell models. We further tested the effects of BMP4 on retinal cells.

Results: The results demonstrated that BMP4 and SMAD9 were highly expressed in both in vivo and in vitro models, while BMP4 could significantly upregulate the expression of SMAD9 and promote the expression of VEGF and fibrosis factors.

Conclusions: This study is the first to analyze the mechanism by which high glucose levels affect retinal vascular endothelial cells through RNA transcriptome sequencing and indicates that BMP4 may be a potential target for the dual-target treatment (anti-VEGF and antifibrosis) of DR.

\section{Background}

As a common and serious complication of diabetes, diabetic retinopathy (DR) has become the leading cause of blindness worldwide [1, 2]. In the last decade, increasing numbers of studies have shown that $\mathrm{DR}$, which is accompanied by retinal neurodegenerative changes, can no longer be regarded simply as a microvascular disease but as a disruption of the retinal neurovascular unit [3, 4]. Epidemiological results suggest that long-term inadequate glycemic control is an important cause of vision loss in DR patients and indicate the role of persistent hyperglycemia in cell dysfunction, oxidative stress and inflammatory response in the course of DR [5-11].

Intravitreal injection of anti-VEGF antibodies has been widely used in the treatment of proliferative diabetic retinopathy (PDR) $[12,13]$. However, the progression and development of fibrovascular membranes and traction retinal detachment followed by elevated connective tissue growth factor (CTGF) levels after anti-VEGF injection cannot be ignored[14, 15]. It is suggested that the effects of both VEGF and CTGF should be considered simultaneously in the treatment of DR to achieve the ultimate goal of dual-target therapy. Therefore, finding new targets to balance the effects of VEGF and CTGF has become an urgent task. 
RNA sequencing (RNA-seq) technology is widely used in basic research, clinical diagnosis, and drug research, taking advantage of the ability to quickly obtain comprehensive transcribed sequence information from specific tissues or organs[16, 17]. In this study, we applied RNA-seq technology to highglucose-treated vascular endothelial cells, extracted the hidden information from an in-depth analysis of the data, and performed repeated verification in multiple models and functional assays. The results clearly demonstrated that BMP4 and SMAD9 are potential novel targets for dual-target treatment of DR.

\section{Methods And Materials 2.1 Cell culture}

We used RF/6A cells (Tianjin Medical University Eye Institute, China) for most experiments. RF/6A cells were grown in RPMI 1640 medium (Gibco, Thermo Fisher Scientific, USA) with 10\% fetal bovine serum and an antibiotic mixture of $100 \mathrm{U} / \mathrm{mL}$ penicillin and $100 \mathrm{U} / \mathrm{mL}$ streptomycin. We also used human retinal capillary endothelial cells (HRCECs) and Müller cells in follow-up verification experiments. HRCECs and Müller cells were stored at the Tianjin Medical University Eye Institute. Both cell lines were grown in high-glucose DMEM (Gibco, Thermo Fisher Scientific) supplemented with $10 \%$ fetal bovine serum and an antibiotic mixture of $100 \mathrm{U} / \mathrm{mL}$ penicillin and $100 \mathrm{U} / \mathrm{mL}$ streptomycin. Cells were passaged when they reached $90 \%$ confluence, and cells at or before six passages were used for experiments. All cells were incubated in a sterile humidified atmosphere at $37^{\circ} \mathrm{C}$ in $5 \% \mathrm{CO}_{2}$.

\subsection{Cell stimulus treatments}

We used high glucose to treat RF/6A cells. RF/6A cells were cultured to nearly $50 \%$ confluence in 6 -well dishes before being starved in serum-free medium overnight. The cells were then divided into two groups: a control group $(\mathrm{N})$ and a high-glucose group $(\mathrm{HG})$. Previously, Lan et al reported the plasma glucose concentration to be approximately $5.8 \mathrm{mM}[16]$. Thus, we used $5 \mathrm{mM}$ glucose in N. Most in vitro studies use $25 \mathrm{mM}$ glucose to treat $\mathrm{HGs}$; thus, we used glucose concentrations of $25 \mathrm{mM}$ in the HG. The cells were stimulated with glucose for 48 hours.

We also used $\mathrm{H}_{2} \mathrm{O}_{2}$ to stimulate the cells. Cultured cells were incubated with different concentrations of $\mathrm{H}_{2} \mathrm{O}_{2}(0,100,200,400,800$ and $1000 \mu \mathrm{mol} / \mathrm{L})$ for different time periods $(1,2,3$ and 4 hours), followed by 24 hours of recovery.

A hypoxic environment was achieved using a dedicated incubator. Hypoxic cell culture conditions were maintained under $2 \%$ oxygen atmosphere (via injection of $\mathrm{N}_{2}$ ). Cells were maintained under hypoxic conditions for three or six hours, after which the culture medium was replaced, and the cells were maintained under normal conditions for follow-up experiments.

Cells were treated with different concentrations of $4 \operatorname{HNE}(5,10,20,40,80$, and $100 \mu \mathrm{M})$, of $\operatorname{CoCl}_{2}(10,25$, $50,100$, and $200 \mu \mathrm{M})$,, or of AGEs $(100,150,200,250$, or $300 \mu \mathrm{g} / \mathrm{ml})$ for 24 hours.

\subsection{Cell proliferation assay}


Cell proliferation was measured using the MTT assay. A total of $3 \times 10^{4}$ cells per well were seeded in 96 well plates. After treatment with different stimulants, $110 \mu \mathrm{l}$ of MTT solution (Solarbio, China) was added into each well and incubated for 4 hours at $37^{\circ} \mathrm{C}$. The MTT in each well was then replaced with $150 \mu \mathrm{L}$ DMSO, and the optical density (OD) at $490 \mathrm{~nm}$ was measured with a microplate reader (Thermo, USA).

\subsection{Wound healing assay}

A total of $2 \times 10^{5} \mathrm{RF}-6 \mathrm{~A}$ cells per well were cultured in 12-well plates. When the cells grew to approximately $80 \%$ confluence, a linear wound was generated by scratching the cells with a sterile pipette tip. The cells were washed twice with PBS and then incubated in RPMI 1640 medium. Cell migration toward the wounds was imaged in the same visual field after 0 and 24 hours with a phase contrast microscope (Olympus, Tokyo, Japan). Cell migration was measured by cellSens Standard software, and the migration rate (\%) was defined as follows: migration rate $=\left(\mathrm{S}_{0}-\mathrm{S}_{\mathrm{t}}\right) / \mathrm{S}_{0} * 100 \%\left(\mathrm{~S}_{0}\right.$ : Raw bare area; $\mathrm{S}_{\mathrm{t}}$ : Bare area at each time point).

\subsection{Transwell assay}

A total of $1 \times 10^{5}$ cells per well were seeded into a Transwell insert (Corning, Tewksbury, MA), and then cultured with culture media without serum. Different stimuli were added to the lower chambers. Cells were subsequently allowed to migrate across the polycarbonate filter for 24 hours at $37^{\circ} \mathrm{C}$. Nonmigrated cells on the top side of the filter were removed by scraping. Migrated cells on the bottom side of the filter were subsequently fixed with $4 \%$ paraformaldehyde (PFA) for $30 \mathrm{~min}$ and stained with $0.1 \%$ crystal violet solution (Solarbio, China) for $20 \mathrm{~min}$. The number of stained cells in five random fields of each well was counted using ImageJ software to determine the average number of migrated cells.

\subsection{Tube formation assay}

Twenty-four-well plates were coated with $300 \mu \mathrm{L}$ Matrigel (BD, San Jose, CA) per well and incubated at $37^{\circ} \mathrm{C}$ for $20 \mathrm{~min}$ to allow the Matrigel to solidify. A total of $1 \times 10^{5}$ cells per well were seeded into the plate and incubated with different stimuli at $37^{\circ} \mathrm{C}$ for 6 hours. The cells in five randomly selected fields per well were then imaged using a Zeiss digital camera.. Tube formation was quantified by measuring the length of capillary structures using ImageJ software. The average tube length in five fields was taken as the value for each sample.

\subsection{RNA-seq}

RNA-seq was performed as previously described. Briefly, total RNA was extracted from cells in different groups, and various parameters reflecting the quality of the extracted total RNA were determined. After determining that the total RNA samples were of high quality, magnetic beads were used to enrich and fragment the mRNA, which has a poly (A) tail, and a library was constructed according to the common New England Biolabs (NEB) library construction method and a chain-specific library construction method. Following library construction, fluorescence quantitative reverse transcription was applied to accurately quantify the concentration of the library (the concentration of the library was greater than $2 \mathrm{nmol} / \mathrm{L}$.) on the basis of preliminary quantification by fluorometer to ensure the quality of the library. After the library 
was qualified, data from the different libraries were collected according to the effective RNA concentration and the demand of the operation data quantity. The Illumina HiSeq/MiSeq sequencer captured the fluorescence signal and converted the optical signal into a sequencing peak through computer software to obtain sequence information on the tested fragments.

\subsection{Gene Ontology (GO) and Kyoto Encyclopedia of Genes and Genomes (KEGG) pathway analyses}

Differential gene expression was determined from the obtained gene expression profiles with the edgeR function in Bioconductor software. The edgeR function assumed that the count of sequencing reads for each gene was a negative binomial distribution, and the hypothesis test was conducted based on this theory. $\mathrm{GO}$ analysis and KEGG pathway analysis were conducted based on the protein sequences encoded by genes exhibiting significant differential expression $(P \leq 0.001)$.

Blast software was used to compare the gene sequences to the nonredundant (nr) database and the KEGG database, followed by the extraction of GO and pathway annotation information for all genes. The top GO function and hypergeometric test in Bioconductor software were used to analyze the $\mathrm{GO}$ and KEGG pathways of the differentially expressed genes. The data were screened for genetic variations, log2 to log2 interval meaningless data were screened and removed, and the data were listed one by one according to the $P$ value for identification. Then, through consulting the relevant literature, we investigated the role of each gene in different tissues and its mechanisms. In addition, according to the role of the genetic pathways, we investigated the relationships between significantly differentially expressed genes.

\subsection{RNA extraction}

Then, $200 \mu \mathrm{L}$ chloroform was added to the samples with TRIzol. After centrifugation at $1200 \mathrm{xg}$ for $10 \mathrm{~min}$ at $4{ }^{\circ} \mathrm{C}$, approximately $500 \mu \mathrm{L}$ of supernatant was transferred into another EP tube. Then, $500 \mu \mathrm{l}$ of isopropanol was added to the EP tube and mixed well. After centrifugation at $1200 \mathrm{xg}$ for $5 \mathrm{~min}$ at $4{ }^{\circ} \mathrm{C}$, the supernatant was discarded, $1 \mathrm{~mL} 75 \%$ ethanol was added, and the sample was centrifuged at 1200 $\mathrm{xg}$ for $5 \mathrm{~min}$ at $4{ }^{\circ} \mathrm{C}$. The supernatant was discarded, and the EP tube was left open in the fume hood for $30 \mathrm{~min}$. When the precipitate in the EP tube was nearly completely dry, $30 \mu \mathrm{LEPC}$ water was added to dissolve the RNA precipitate, and the mRNA concentration was detected and recorded with an enzyme marker.

\subsection{Reverse transcriptionquantitative PCR (RT-qPCR)}

We chose six significantly differentially expressed genes for RTqPCR validation. RT-qPCR was performed using purified RNA from six kinds of samples: high-glucose-cultured RF-6A cells, diabetic patient blood, and HRCECs and Müller cells under hypoxic conditions or oxidative stress.

Total RNA was extracted, and the RNA concentration was detected by ultramicro spectrophotometer. An A260/A280 ratio between 1.8 and 2.0 was considered sufficient to use the RNA in subsequent reverse 
transcription reactions. The total RNA was reverse transcribed into CDNA by a Revert Aid First Strand cDNA Synthesis kit (Thermo Fisher Scientific, USA) according to the manufacturer's instructions. GAPDH was used as a reference control for RT-qPCR, and Primer Express 3.0 was used to design primer sequences, which are listed in Table S1. Two microliters of CDNA, $2 \mu$ of primers and $4 \mu$ l of SYBR were mixed and added to 384-well plates, after which RT-qPCR was performed in a real-time PCR instrument (Life Technologies, USA).

The thermal cycling conditions for qPCR were as follows: 40 cycles of $50^{\circ} \mathrm{C}$ for $2 \min , 95^{\circ} \mathrm{C}$ for $10 \min$, and $95^{\circ} \mathrm{C}$ for $15 \mathrm{sec}$, followed by $55^{\circ} \mathrm{C}$ for $15 \mathrm{sec}$ and $72{ }^{\circ} \mathrm{C}$ for $30 \mathrm{sec}$, followed by a dissociation stage $\left(95^{\circ} \mathrm{C}\right.$ for $15 \mathrm{sec}, 60{ }^{\circ} \mathrm{C}$ for $15 \mathrm{sec}, 95^{\circ} \mathrm{C}$ for $15 \mathrm{sec}$ ). Relative gene expression levels were calculated with the $2^{\Delta \Delta C t}$ method.

\subsection{Peripheral blood mononuclear cell isolation}

Blood was collected in an EDTA anticoagulant tube. After centrifugation at $1800 \mathrm{xg}$ for $5 \mathrm{~min}$, the lower red liquid was diluted with an equal amount of PBS a room temperature Ficoll peripheral blood lymphocyte gradient was added to the diluted blood.

After centrifugation at $1200 \mathrm{xg}$ for $20 \mathrm{~min}$, the liquid in the centrifuge tube was layered. The middle white film layer was carefully aspirated with a pipette and placed in another $15 \mathrm{~mL}$ centrifuge tube, and $1 \mathrm{~mL}$ TRIzol was added to the white precipitate after washing. Finally, the samples were stored at $-80^{\circ} \mathrm{C}$.

\subsection{Immunofluorescence}

Cells or tissues were fixed in 4\% PFA for 20 min and then incubated in $0.1 \%$ Triton X-100 for 10 min, followed by a one hour incubation in blocking solution consisting of $10 \%$ goat serum, $0.1 \%$ Tween 20 , and 1\% BSA in PBS. Cells or tissues were incubated with rabbit anti-SMAD9 (Bioss, China) diluted 1:400 in goat serum blocking solution and rabbit anti-BMP4 (Boster, China) diluted 1:20 in goat serum blocking solution at $4{ }^{\circ} \mathrm{C}$, followed by the addition of goat anti-rabbit IgG H\&L (Alexa Fluor $\left.{ }^{\circledR} 488\right)(1: 500$, Abcam, UK). Nuclei were stained with 4',6-diamidino-2-phenylindole (DAPI). The cells or tissues were observed under a fluorescence microscope (U-LH100L-3, Olympus Corporation, Tokyo, Japan).

\subsection{Western blot}

Cells were lysed in lysis buffer (50 mM Tris, pH 7.4, $150 \mathrm{mM} \mathrm{NaCl}, 1 \%$ Triton X-100, 0.1\% SDS, and 1\% sodium deoxycholate). Thirty micrograms of protein lysate was separated by a $10 \%$ SDS-PAGE gel and then transferred to a polyvinylidene difluoride membrane (Millipore, USA). The primary antibodies used were anti-SMAD9 (1:1000; Bioss, China) and anti-BMP4 (1:1000; Boster, China). Anti-GAPDH antibody (1:1000; Cell Signaling Technology, Beverly, MA, USA) was used as a loading control. Protein bands were 
visualized by ECL (Amersham Pharmacia Biotech, Arlington Height, IL, USA) on an X-ray film, which was quantified by ImageJ software (National Institutes of Health, Bethesda, MD, USA).

\subsection{Streptozotocin (STZ)-induced diabetes in mice}

Diabetes was induced in 6- to 8-week-old adult male Sprague-Dawley (SD) rats (200-220 g). The rats were housed 3 per cage under a 12/12-hour light/dark cycle at a temperature of 19 to $23^{\circ} \mathrm{C}$. The rats were randomly divided into two groups: a normal group and a diabetic group. Then, rats in the diabetic group received a caudal injection of a freshly prepared solution of streptozotocin at $55 \mathrm{mg} / \mathrm{kg}$ bodyweight. Three days after injection, we measured the blood glucose levels of the rats, and rats with a blood glucose level of $16.7 \mathrm{mmol} / \mathrm{L}$ or higher were considered to have diabetes.

\subsection{Statistical analysis}

One-way analysis of variance (ANOVA) and independent samples $T$ tests were used to assess the significance of differences between groups, and the data are presented as the mean \pm standard deviation (SD). All experiments were repeated at least three times, and $\mathrm{P}<0.05$ indicated statistically significant differences.

\section{Results}

\subsection{Effects of high glucose-induced cell proliferation, migration and tube formation in RF/6A cells}

Hyperglycemia is an important factor leading to DR, so we constructed a model of retinal vascular endothelial cells induced by hyperglycemia in vitro to explore the pathogenesis of DR. An in vitro MTT assay was carried out to examine the proliferative ability of RF/6A cells after the cells had been treated with high glucose $(25 \mathrm{mM})$ for 24 hours. The results showed that $25 \mathrm{mM}$ glucose treatment significantly increased the proliferation of RF/6A cells compared with $5 \mathrm{mM}$ glucose treatment.

A wound scratching assay and transwell assay were conducted to examine whether high glucose levels were able to modulate the migration of RF/6A cells. The results showed that $25 \mathrm{mM}$ glucose significantly accelerated the wound closure and increased the number of migrating cells compared with the $5 \mathrm{mM}$ glucose treatment.

To examine the effect of glucose $(25 \mathrm{mM})$ on angiogenesis, the tube formation of RF/6A cells was evaluated by Matrigel assay. The results showed that $25 \mathrm{mM}$ glucose significantly increased the number of capillary-like structures compared with the $5 \mathrm{mM}$ glucose treatment. 
Upon stimulation with high glucose, the proliferation ability, migration ability and lumen formation ability of retinal vascular endothelial cells were significantly improved, indicating that the high glucose model was successfully established and could be used for the RNA-seq analysis in the next step (FigS1).

\subsection{Sample quality and gene expression levels}

To obtain precise results, three RF/6A cell samples were selected from the control and high-glucose groups. The total number of reads from the control group and the high-glucose group were 47865006 and 46731260, respectively, and there was no significant difference between the numbers of reads between the two groups. On average, $61.59 \%$ of the total reads were mapped to the reference genome. Detailed sample quality data are listed in Table S2.

We analyzed differences in gene expression between the two different groups. Compared with gene expression in the control group, high-glucose treatment changed the expression of 449 genes. Of these 449 differentially expressed genes, 297 were upregulated and 152 were downregulated, and the top 20 significantly differentially expressed genes are listed in Table S3. To further investigate differentially expressed genes in the high-glucose-treated RF/6A cells, we explored pathway enrichment with the KEGG database. KEGG pathway enrichment analysis revealed the involvement of the differentially expressed genes in 207 pathways, including the TGF-beta signaling pathway. KEGG pathway enrichment results are presented in Fig. 1.

\subsection{Confirmation of differentially expressed genes in glucose-induced RF/6A cells}

To confirm the RNA-seq findings, we validated the expression of six genes by RT-qPCR in the sequenced samples. These six genes were SMAD9, BMP4, DAB1, ATP1A3, CHST5, and UNC5C. These genes are involved in cancer, cardiovascular disease and other diseases, but their involvement in DR has not been shown. BMP4 was previously shown to be involved in regulating VEGF. BMP4, SMAD9, DAB1 and CHST5 are related to extracellular matrix metabolism. ATP1A3 regulates the $\mathrm{Na}^{+} / \mathrm{K}^{+}$ATP enzyme system, causing ischemia and apoptosis in ganglion cells. Moreover, UNC5C can also cause apoptosis in ganglion cells.

From the RT-qPCR data, we found that the expression of SMAD9 and BMP4 was significantly increased in the sequenced samples, which is consistent with their expression levels determined by RNA-seq, indicating that high glucose can upregulate the expression of the SMAD9 and BMP4 genes. Moreover, we used immunofluorescence and western blot to determine the expression and distribution of SMAD9 and BMP4 in high-glucose-treated RF/6A cells. From the immunofluorescence and western blot results, we found that BMP4 and SMAD9 expression was significantly higher in high-glucose-treated cells than in the $5 \mathrm{mM}$ glucose treatment group.

\subsection{Confirmation of differentially expressed genes in blood samples}


To characterize the expression of these differentially expressed genes in DR patients, we collected blood samples from 20 diabetic patients and 20 normal people and extracted peripheral blood monocytes to detect the expression of these differentially expressed genes. Before testing gene expression, we conducted statistical analysis on the baseline data on gender, age, BMI and other clinical data of the study subjects, and the results showed that there were no significant differences in the baseline data except for HBA1c and fasting blood glucose (Table S4, S5).

We detected the expression of the six selected differentially expressed genes in patients through RT-qPCR, and the results showed that BMP4 and SMAD9 were highly expressed, which was consistent with the RNA-seq results and the results verified in the original model. We further analyzed BMP4 and SMAD9 in each patient with DR. The details of each patient are listed in the table below, and the results showed that the expression of these two genes was enhanced in the patient blood samples (Fig. 3).

\subsection{Characterization of the expression of BMP4 and SMAD9 in the retinas of STZ-induced diabetic rats}

To better understand the possible role of BMP4 and SMAD9 in DR, we attempted to determine the expression and distribution of these two genes in the retina. Since human retinal specimens are difficult to obtain, we selected rat retinas to observe the expression of these two genes. We first established a STZ-induced DR rat model, and by measuring changes in blood glucose and body weight, we found that all STZ-induced rats displayed typical diabetic symptoms of polyphagia, polydipsia, polyuria, and emaciation, and the blood sugar concentration was significantly higher in the STZ-induced rats than in the control rats. From HE staining, we observed that compared to that of the retinas of normal rats, the arrangement of retinal cells of diabetic rats became disordered, and microvascular expansion and microvascular lesions were observed. These changes indicated that our diabetic rat model was successfully established. To validate the expression of BMP4 and SMAD9, retinas from diabetic and normal rats were prepared for RT-qPCR, immunofluorescence and western blot experiments. As shown in Fig. 5, we found that BMP4 and SMAD9 were distributed throughout the rat retina and were more highly expressed in diabetic rats than in normal rats. To further investigate the distribution and expression of these two genes in the retina, we examined them in an in vitro cell model.

\subsection{Characterization of the expression of BMP4 and SMAD9 in an HRCEC DR model}

Since the blood of diabetic patients and the retina of diabetic rats can only be used to study the expression of differentially expressed genes at the overall level, we constructed a DR cell model in vitro to further study the distribution and expression of BMP4 and SMAD9. Since DR is also a vascular disease, we first observed the expression of these two genes in HRCECs. In addition, DR is a multifactorial disease, so HRCECs were stimulated in $\mathrm{H}_{2} \mathrm{O}_{2}$, hypoxia, 4HNE, AGEs and $\mathrm{CoCl}_{2}$. 
We used the MTT assay, wound scratching assay and tube formation assay to explore the effects of these five stimulation methods on HRCECs. The results showed that hypoxia, $4 \mathrm{HNE}$ and $\mathrm{CoCl}_{2}$ could promote the proliferation, migration and tube formation of HRCECs, while $\mathrm{H}_{2} \mathrm{O}_{2}$ and AGE stimulation could suppress these angiogenesis processes. The results were statistically significant, indicating that these five HRCEC DR models had been successfully established. Next, we aimed to verify the expression of differentially expressed genes in the HRCEC DR cell models (FigS2).

Based on the successful establishment of the model, we detected the expression of BMP4 and SMAD9 in the five HRCEC models by PCR, western blotting and immunofluorescence. The results showed that the expression of these two genes was increased at both the RNA and protein levels, with statistically significant differences. Next, we aimed to verify the expression of these two genes in other cell models.

\subsection{Characterization of the expression of BMP4 and SMAD9 in Müller DR cell models}

Since DR is a neurovascular disease that can cause neuropathy in addition to microvascular lesions, we explored whether BMP4 and SMAD9 could be detected in Müller cells and investigated their expression in the Müller cell models of DR. We used the MTT assay, wound scratching assay and Matrigel assay to observe the effect of $\mathrm{H}_{2} \mathrm{O}_{2}$, hypoxia, $4 \mathrm{HNE}$, AGEs and $\mathrm{CoCl}_{2}$ on the proliferation and migration ability of Müller cells.

The results showed that $\mathrm{H} 2 \mathrm{O} 2$, hypoxia and 4HNE could promote the proliferation and migration of Müller cells, while AGEs and $\mathrm{CoCl} 2$ inhibited the proliferation and migration of Müller cells. These results indicated the establishment of DR in Müller cells, and next we verified BMP4 and SMAD9 expression in these five cell models (FigS3).

The proliferation, migration and other assays, showed that a DR Müller cell model had been successfully established, based on the detection of the distribution and expression of BMP4 and SMAD9 in these models by PCR, western blotting and immunofluorescence. The results showed that these two genes were highly expressed in the DR Müller cell model (FigS4).

\subsection{Characterization of the expression of BMP4 and SMAD9 in DR RPE cell models}

RPE is located between the choroid and the neurosensory retina and forms the external retinal barrier, and RPE cells also play a significant role in DR. Therefore, we measured the expression of the two genes in RPE cells affected by DR. We treated RPE cells with $\mathrm{H}_{2} \mathrm{O}_{2}$, hypoxia, $4 \mathrm{HNE}, \mathrm{AGEs}$ and $\mathrm{CoCl}_{2}$ to simulate the DR eye microenvironment, and we used the MTT assay, wound scratching assay and Matrigel assay to observe whether these cell models were successfully established. From the results, we can see that these five stimuli significantly promoted the proliferation and migration of RPE cells. Next, we detected the expression of BMP4 and SMAD9 in these established cell models (FigS5). 
We determined that the RPE cell model for DR was successfully established by a variety of methods. Next, we examined the expression of the differentially expressed genes BMP4 and SMAD9 in these five cell models. The results showed that by PCR, immunofluorescence and western blotting, BMP4 and SMAD9 were significantly increased at both the protein and RNA levels in the RPE cell model, with statistically significant differences (FigS6).

\subsection{Exploring the effect of BMP4 on DR in retinal cells}

In a previous work, to eliminate the false positive results of RNA-seq, we verified the expression of BMP4 and SMAD9 in the blood of diabetic patients, in vivo animal models and a variety of cell models in vitro, and the results showed that these two molecules were highly expressed in a variety of models. Next, to further clarify the role of these two genes in DR, we first explored the relationship between BMP4 and SMAD9 through immunofluorescence, western blotting and PCR, and the results showed that BMP4 could promote the expression of SMAD9. Next, we stimulated RF/6A, HRCEC, Müller and RPE cells with BMP4 and determined that BMP4 could significantly promote the proliferation and migration of retinal cells, as demonstrated by MTT and wound scratch assays. In addition, we explored the function of retinal vascular endothelial cells induced by BMP4, and the results showed that BMP4 could significantly promote the expression of VEGF and fibrosis-related factors in vascular endothelial cells.

\section{Discussion}

It is known that retinal neovascularization and fibrotic membranes are hallmarks of PDR[18]. Anti-VEGF drugs have gradually become an effective way to assist the treatment of PDR due to their significant effect on neovascular and exudative lesions [13]. However, a large number of studies have found that anti-VEGF drug therapy can lead to increased expression of fibrotic factors and aggravate the fibrotic process $[19,20]$. Previous studies have found that CTGF expression in the proliferative membrane of PDR patients treated with anti-VEGF drugs was significantly decreased, but fibrotic factor expression was significantly upregulated [21]. Therefore, we also hope to explore novel dual-target therapies for DR by mining its pathogenesis.

In the present study, we used RF/6A cells stimulated with high glucose levels to simulate the ocular environment in DR patients to some extent. Stimulation with high glucose levels could promote the proliferation and migration of cells, indicating the remarkable influence of a high glucose state on the biological characteristics of RF/6A cells. To further understand the mechanism by which high glucose levels affect vascular endothelial cells, we used RNA-seq to comprehensively sequence transcripts in a DR cell model. With the accurate and quantitative recognition of molecular markers by RNA-seq, we successfully identified two differentially expressed genes, BMP4 and SMAD9, which belong to the TGF- $\beta$ pathway.

Bone morphogenetic proteins (BMPs), members of the TGF- $\beta$ family, are involved in many cellular functions[22]. BMP4, a member of the BMP family, is involved in eye development, including protecting Müller glial cells in the chicken retina, promoting cell invasion and migration in malignant melanoma and 
smooth muscle, regulating the transcription and secretion of the VEGF gene in ARPE-19 cells and zebrafish embryos, and contributing to renal fibrosis[23-28]. In detail, BMP4 increased VEGF secretion in a dose- and time-dependent manner by binding to BMP-activated SMAD-binding elements, affecting the phosphorylation of R-SMADs (SMAD1, SMAD5, and SMAD9) and forming complexes with Smad4, which ultimately activate BMP target genes [29-32]. BMP4 affects the phosphorylation of SMAD9 and forms complexes with Smad4, which finally induces BMP target genes. Many studies have shown the upregulation of SMAD9 expression by BMP4 in many cell types, such as C2C12, H9c2, 3T3-L1, HepG2, B16 cells and primary fibroblasts [33,34]. Moreover, BMP4 significantly increased the collagen production of fibroblasts and induced the differentiation of fibroblasts into myofibroblasts [35]. In a variety of cells, high expression of BMP4 significantly upregulates extracellular components, including FN, PAI-1, collagen, and platelet-reactive protein 1. Therefore, BMP4 and SMAD9 may function as partners to play a role in angiogenesis and fibrosis in DR.

Binding of BMP4 to the TGF- $\beta$ receptor initiates SMAD9 phosphorylation and translocation into the nucleus from the cytoplasm. Afterwards, a functional protein complex consisting of SMAD4 and SMAD9 is formed, which leads to up-regulate the transcription and secretion of the VEGF gene and the promotion of extracellular matrix formation.

Considering that RNA-seq may contain false-positive results, in order to minimize this possibility, we tried our best to confirm the expression of the identified differential genes by establishing multiple DR models in diverse cell types. We first measured the expression of these two genes in the blood of people with diabetes. In DR, blood is the most practical and clinically significant experimental sample. The expression of the two factors in patient blood samples was measured to fully represent the true distribution of these two factors in DR patients. We collected blood from 20 diabetic patients and 20 healthy subjects and isolated monocytes. In the RNA extracted from peripheral blood lymphocytes, we detected the expression of these two genes by PCR. We studied the expression level of these two genes in the 20 patients on average and in each diabetic patient. The results showed that the expression of BMP4 and SMAD9 was increased in peripheral blood lymphocytes of diabetic patients, and the expression was increased in each diabetic patient.

Then, we detected the expression of these two genes in STZ-induced rat retinas. Since these two genes are highly expressed in DR, it is necessary and meaningful to detect the expression and distribution of these two genes in retinal samples. However, since it is difficult to obtain human retinal samples, we chose rat retinas as the most genetically similar experimental model available to us. The immunofluorescence results on rat retinas demonstrated that BMP4 and SMAD9 are highly expressed in all layers of the retina. Then, we extracted RNA and protein from the rat retinas, and the results showed that the expression of BMP4 and SMAD9 was upregulated at both the RNA and protein levels.

By studying the expression of BMP4 and SMAD9 in the blood of DR patients and in rat retinas, we adopted a comprehensive approach to understand the distribution of these molecules. The abovementioned results demonstrate that DR is a disease resulting from multiple factors that affects 
multiple cells. Subsequently, we designed a series of assays to verify the expression of BMP4 and SMAD9 in diverse disease models with multiple cell types. Therefore, considering the involvement of the neurovascular unit, we studied the expression of BMP4 and SMAD9 in HRCEC, Müller and RPE cell models, which are the representative cellular components of the neurovascular unit. DR is a multifactorial disease, and classical theories suggest that it is caused by the accumulation of glycosylated end products, lipid metabolism disorders, oxidative stress and so on. Therefore, in this study, we used five different methods to stimulate cells to mimic the microenvironment of retinal cells in DR from different perspectives. Oxidative stress is associated with $\mathrm{DR}$, so we used $\mathrm{H}_{2} \mathrm{O}_{2}$ to stimulate cells [36]. The effects of hypoxia and $\mathrm{CoCl}_{2}$ represent the physical and chemical characteristics of ischemic hypoxia in DR [37, 38]. In addition, 4HNE was used to simulate the accumulation of lipids during the DR process, and AGEs were used to simulate the accumulation of glycosylated end products in the DR process [39, 40]. We first used cell viability, migration and lumen formation assays to observe the effects of these stimuli on cell proliferation, migration and other biological characteristics and to determine whether each cell model was successfully established. Then, we examined the BMP4 and SMAD9 expression in these cell models, and the results showed that the increased expression of these two genes in the different cell models was consistent with the RNA-seq results.

We also stimulated different retinal cells (RF/6A, HRCEC, Müller and RPE) with BMP4 to observe the effect of BMP4 on multiple retinal cells. We found that BMP4 significantly affected the proliferation, migration and lumen formation of a variety of retinal cells. Moreover, we also observed the regulatory effect of BMP4 on SMAD9 and the effect of these two factors on the cellular functions of multiple retinal cells. From the experimental results, we found that after treating cells with BMP4, the expression of SMAD9 was significantly increased at both the RNA and protein levels. Under the condition of high levels of both BMP4 and SMAD9, the expression of fibrosis-related factors and VEGF in cells was significantly upregulated, which further confirmed our previous hypothesis. Therefore, BMP4 and SMAD9 may function together to play a role in angiogenesis and fibrosis in DR.

In recent years, a consensus has been reached in the field of ophthalmology, whereby the inhibition of the formation of new blood vessels and the control of fibrosis are considered equally important in the treatment of $\mathrm{DR}$, and some pioneers have proposed the idea of dual-target therapy and have exerted considerable efforts in putting it into practice. They used VEGF inhibitors and anti-CTGF shRNA simultaneously to treat diabetic rats and found that the therapy could help restore normal transcription levels of CTGF and VEGF and improve retinal vascular dysfunction[41]. In comparison, BMP4, which is the focus of our study, is capable of killing two birds with one stone, namely, regulating the expression of CTGF and VEGF simultaneously. Another significant advantage is that the factors related to fibrosis affected by BMP4 are far more than just CTGF, FN, and laminin a. Both SMA and collagen I are also under its control.

\section{Conclusions}


In conclusion, effectively antagonizing BMP4 can not only inhibit the expression of VEGF, that is, the formation of new blood vessels and the occurrence of leakage, but it will also certainly play a more extensive role in antifibrosis, that is, the formation of fibrous membranes. In summary, we propose a new perspective to achieve dual-target therapy of PDR by antagonizing BMP4.

\section{Abbreviations}

4', 6-diamidino-2-phenylindole (DAPI); Diabetic retinopathy (DR); Gene Ontology (GO); Human retinal capillary endothelial cells (HRCECs); Kyoto Encyclopedia of Genes and Genomes (KEGG); 3-(4,5dimethylthiazol-2-yl)-2,5-diphenyltetrazolium bromide (MTT); New England Biolabs (NEB); Nonredundant (nr); Paraformaldehyde (PFA); RNA sequencing (RNA-seq); Reverse transcription-quantitative PCR (RTqPCR);Sprague-Dawley (SD); Streptozotocin (STZ).

\section{Declarations}

\section{Ethical Approval and Consent to participate}

All animal experiments were approved by the Animal Ethical and Welfare Committee of Tianjin Medical University Eye Institute..

\section{Consent for publication}

Not applicable

\section{Availability of supporting data}

All data generated or analysed during this study are included in this published article.

\section{Competing interests}

The authors report no conflicts of interests. The authors alone are responsible for the content and writing of the paper.

\section{Funding}

This study was supported by the National Natural Science Funds (81570872), China; National Natural Science Foundation of China (81670875) $₫ T$ Tianjin municipal health and family planning commission young medical talents project, Tianjin, China; Tianjin medical university eye hospital young innovative talents project (YDYYRCXM-C2018-02), Tianjin, China; Tianjin education commission research project (2018KJ063), Tianjin, China; Bethune Merck Diabetes Research Foundation; Tianjin clinical key discipline construction project (TJLCZDXKM010), Tianjin, China; Tianjin Medical University Eye Hospital Clinical research fund (2016LCKY005).

\section{Authors' contributions}


Li Jiedong designed the research; Xiaorong Li provided advice and guidance; Zhe Zhang and Xun Liu performed the research; Zhe Zhang and Juping Liu wrote the paper. All authors read and approved the final manuscript.

\section{Acknowledgements}

The authors thank all clinical laboratory colleagues for assistance with the regular blood sample collection. We are also thankful for the support and assistance from the Tianjin medical university eye institute biobank.

Authors' information

Lijie Dong and Zhe Zhang contributed equally to this manuscript

Correspondence authors are Dr Juping Liu and Professor Xiaorong Li and Dr Lijie Dong.

\section{References}

1. Eshaq RS, Aldalati AMZ, Alexander JS, Harris NR: Diabetic retinopathy: Breaking the barrier. Pathophysiology 2017, 24:229-241.

2. Gangwani RA, Lian JX, McGhee SM, Wong D, Li KK: Diabetic retinopathy screening: global and local perspective. Hong Kong Med J 2016, 22:486-495.

3. Simo R, Hernandez C, European Consortium for the Early Treatment of Diabetic R: Neurodegeneration in the diabetic eye: new insights and therapeutic perspectives. Trends Endocrinol Metab 2014, 25:2333.

4. Gardner TW, Davila JR: The neurovascular unit and the pathophysiologic basis of diabetic retinopathy. Graefes Arch Clin Exp Ophthalmol 2017, 255:1-6.

5. Hernandez C, Simo-Servat A, Bogdanov P, Simo R: Diabetic retinopathy: new therapeutic perspectives based on pathogenic mechanisms. J Endocrinol Invest 2017, 40:925-935.

6. Khalil H: Diabetes microvascular complications-A clinical update. Diabetes Metab Syndr 2017, 11 Suppl 1:S133-S139.

7. Wong TY, Cheung CM, Larsen M, Sharma S, Simo R: Diabetic retinopathy. Nat Rev Dis Primers 2016, 2:16012.

8. Beltramo E, Lopatina T, Berrone E, Mazzeo A, lavello A, Camussi G, Porta M: Extracellular vesicles derived from mesenchymal stem cells induce features of diabetic retinopathy in vitro. Acta Diabetol 2014, 51:1055-1064.

9. Kang H, Ma X, Liu J, Fan Y, Deng X: High glucose-induced endothelial progenitor cell dysfunction. Diab Vasc Dis Res 2017, 14:381-394.

10. Stitt AW, Curtis TM, Chen M, Medina RJ, McKay GJ, Jenkins A, Gardiner TA, Lyons TJ, Hammes HP, Simo R, Lois N: The progress in understanding and treatment of diabetic retinopathy. Prog Retin Eye 
Res 2016, 51:156-186.

11. Gogula SV, Divakar C, Satyanarayana C, Kumar YP, Lavanaya VS: Computational investigation of pkcbeta inhibitors for the treatment of diabetic retinopathy. Bioinformation 2013, 9:1040-1043.

12. Bressler NM, Beaulieu WT, Bressler SB, Glassman AR, Melia BM, Jampol LM, Jhaveri CD, Salehi-Had H, Velez G, Sun JK, Network DR: ANTI-VASCULAR ENDOTHELIAL GROWTH FACTOR THERAPY AND RISK OF TRACTION RETINAL DETACHMENT IN EYES WITH PROLIFERATIVE DIABETIC RETINOPATHY: Pooled Analysis of Five DRCR Retina Network Randomized Clinical Trials. Retina 2019.

13. Karpilova MA, Durzhinskaya MH: [Anti-VEGF drugs in the treatment of neovascular glaucoma]. Vestn Oftalmol 2019, 135:299-304.

14. Klaassen I, van Geest RJ, Kuiper EJ, van Noorden CJ, Schlingemann RO: The role of CTGF in diabetic retinopathy. Exp Eye Res 2015, 133:37-48.

15. Yang H, Huang Y, Chen X, Liu J, Lu Y, Bu L, Xia L, Xiao W, Chen M, Nie Q, Liu Z: The role of CTGF in the diabetic rat retina and its relationship with VEGF and TGF-beta(2), elucidated by treatment with CTGFsiRNA. Acta Ophthalmol 2010, 88:652-659.

16. Wang Z, Gerstein M, Snyder M: RNA-Seq: a revolutionary tool for transcriptomics. Nat Rev Genet 2009, 10:57-63.

17. Mantione KJ, Kream RM, Kuzelova H, Ptacek R, Raboch J, Samuel JM, Stefano GB: Comparing bioinformatic gene expression profiling methods: microarray and RNA-Seq. Med Sci Monit Basic Res 2014, 20:138-142.

18. Stewart MW, Browning DJ, Landers MB: Current management of diabetic tractional retinal detachments. Indian J Ophthalmol 2018, 66:1751-1762.

19. Osaadon P, Fagan XJ, Lifshitz T, Levy J: A review of anti-VEGF agents for proliferative diabetic retinopathy. Eye (Lond) 2014, 28:510-520.

20. Chandra S, Arpa C, Menon D, Khalid H, Hamilton R, Nicholson L, Pal B, Fasolo S, Hykin P, Keane PA, Sivaprasad S: Ten-year outcomes of antivascular endothelial growth factor therapy in neovascular age-related macular degeneration. Eye (Lond) 2020.

21. Kuiper EJ, Van Nieuwenhoven FA, de Smet MD, van Meurs JC, Tanck MW, Oliver N, Klaassen I, Van Noorden CJ, Goldschmeding R, Schlingemann RO: The angio-fibrotic switch of VEGF and CTGF in proliferative diabetic retinopathy. PLOS One 2008, 3:e2675.

22. Schmitt JM, Hwang K, Winn SR, Hollinger JO: Bone morphogenetic proteins: an update on basic biology and clinical relevance. J Orthop Res 1999, 17:269-278.

23. Mathura JR, Jr., Jafari N, Chang JT, Hackett SF, Wahlin KJ, Della NG, Okamoto N, Zack DJ, Campochiaro PA: Bone morphogenetic proteins-2 and -4: negative growth regulators in adult retinal pigmented epithelium. Invest Ophthalmol Vis Sci 2000, 41:592-600.

24. Vogt RR, Unda R, Yeh LC, Vidro EK, Lee JC, Tsin AT: Bone morphogenetic protein-4 enhances vascular endothelial growth factor secretion by human retinal pigment epithelial cells. J Cell Biochem 2006, 98:1196-1202. 
25. Fischer AJ, Schmidt M, Omar G, Reh TA: BMP4 and CNTF are neuroprotective and suppress damageinduced proliferation of Muller glia in the retina. Mol Cell Neurosci 2004, 27:531-542.

26. Rothhammer T, Poser I, Soncin F, Bataille F, Moser M, Bosserhoff AK: Bone morphogenic proteins are overexpressed in malignant melanoma and promote cell invasion and migration. Cancer Res 2005, 65:448-456.

27. He C, Chen X: Transcription regulation of the vegf gene by the BMP/Smad pathway in the angioblast of zebrafish embryos. Biochem Biophys Res Commun 2005, 329:324-330.

28. Frank $\mathrm{D}$, Johnson J, de Caestecker M: Bone morphogenetic protein 4 promotes vascular remodeling in hypoxic pulmonary hypertension. Chest 2005, 128:590S-591S.

29. Bier E, De Robertis EM: EMBRYO DEVELOPMENT. BMP gradients: A paradigm for morphogenmediated developmental patterning. Science 2015, 348:aaa5838.

30. Brazil DP, Church RH, Surae S, Godson C, Martin F: BMP signalling: agony and antagony in the family. Trends Cell Biol 2015, 25:249-264.

31. Bragdon B, Moseychuk O, Saldanha S, King D, Julian J, Nohe A: Bone morphogenetic proteins: a critical review. Cell Signal 2011, 23:609-620.

32. Miyazono K, Kamiya Y, Morikawa M: Bone morphogenetic protein receptors and signal transduction. J Biochem 2010, 147:35-51.

33. Cheng KH, Ponte JF, Thiagalingam S: Elucidation of epigenetic inactivation of SMAD8 in cancer using targeted expressed gene display. Cancer Res 2004, 64:1639-1646.

34. Katakawa Y, Funaba M, Murakami M: Smad8/9 Is Regulated Through the BMP Pathway. J Cell Biochem 2016, 117:1788-1796.

35. Koli K, Myllarniemi M, Vuorinen K, Salmenkivi K, Ryynanen MJ, Kinnula VL, Keski-Oja J: Bone morphogenetic protein-4 inhibitor gremlin is overexpressed in idiopathic pulmonary fibrosis. Am J Patho/ 2006, 169:61-71.

36. Ellis EA, Guberski DL, Somogyi-Mann M, Grant MB: Increased H2O2, vascular endothelial growth factor and receptors in the retina of the BBZ/Wor diabetic rat. Free Radic Biol Med 2000, 28:91-101.

37. Osera C, Martindale JL, Amadio M, Kim J, Yang X, Moad CA, Indig FE, Govoni S, Abdelmohsen K, Gorospe M, Pascale A: Induction of VEGFA mRNA translation by $\mathrm{CoCl} 2$ mediated by HuR. RNA Biol 2015, 12:1121-1130.

38. Gu L, Xu H, Zhang C, Yang Q, Zhang L, Zhang J: Time-dependent changes in hypoxia- and gliosisrelated factors in experimental diabetic retinopathy. Eye (Lond) 2019, 33:600-609.

39. Lei XW, Li Q, Zhang JZ, Zhang YM, Liu Y, Yang KH: The Protective Roles of Folic Acid in Preventing Diabetic Retinopathy Are Potentially Associated with Suppressions on Angiogenesis, Inflammation, and Oxidative Stress. Ophthalmic Res 2019, 62:80-92.

40. Stitt AW: AGEs and diabetic retinopathy. Invest Ophthalmol Vis Sci 2010, 51:4867-4874.

41. Hu B, Zhang Y, Zeng Q, Han Q, Zhang L, Liu M, Li X: Intravitreal injection of ranibizumab and CTGF shRNA improves retinal gene expression and microvessel ultrastructure in a rodent model of 


\section{Figures}

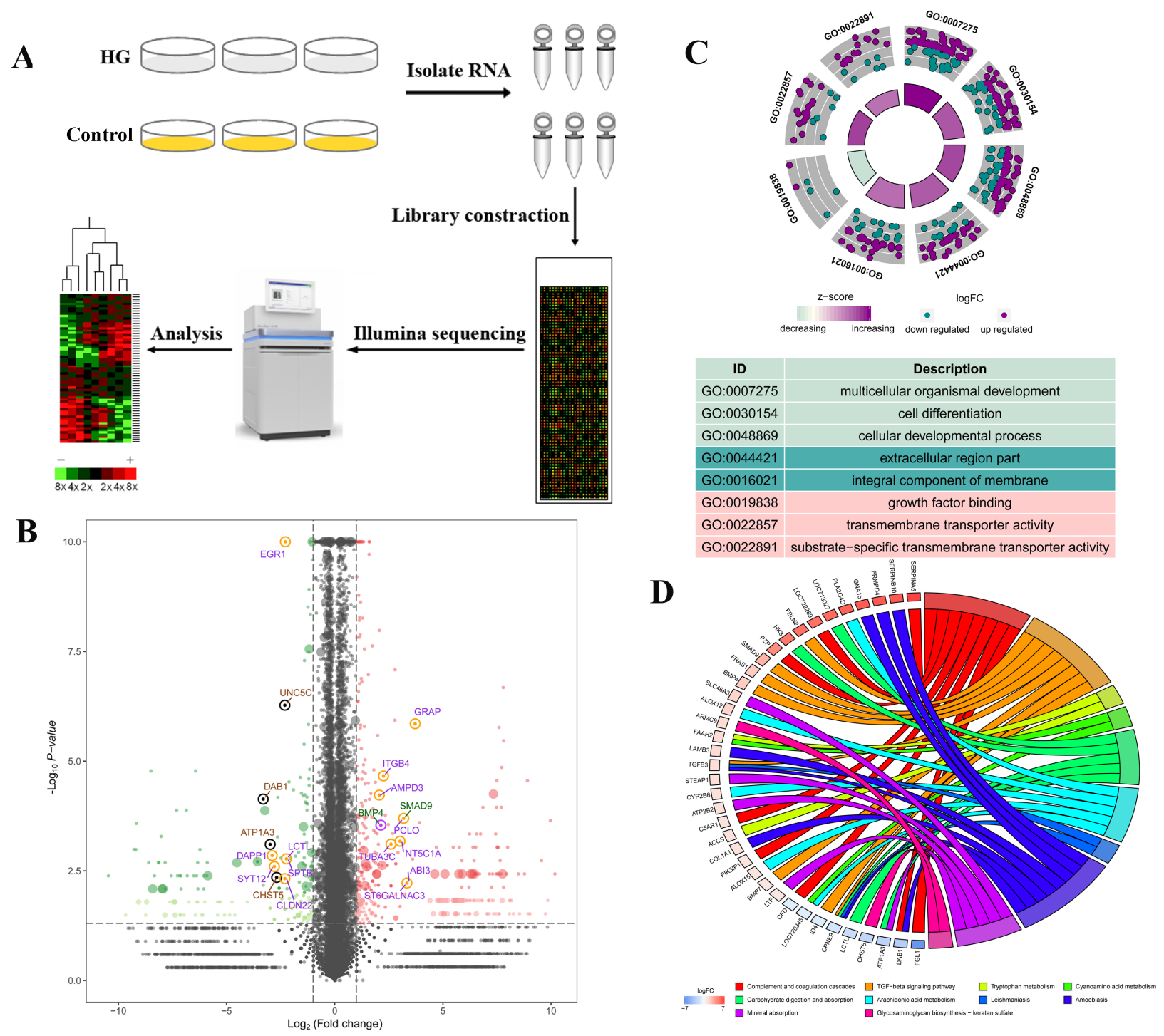

Figure 1

Differentially expressed genes (DEGs) between the two groups were determined through RNA-seq analysis. (A) Schematic flowchart of RNA-seq analysis. (B) Volcano plot of the DEGs. The X-axis represents the log2-fold change in genes expressed at high (positive values) and low (negative values) levels. Significantly upregulated genes $(\log 2(F C)>2$ and $P<0.05)$ are represented by red spots, while downregulated genes $(\log 2(\mathrm{FC})<-2$ and $\mathrm{P}<0.05)$ are represented by green spots. (C) Results of $\mathrm{GO}$ enrichment analysis of DEGs categorized by biological process (BP), molecular function (MF), and cellular component (CC). DEGs enriched in the BP, MF, and CC terms by $\mathrm{GO}$ enrichment analysis with the smallest significance level using Fisher's exact test are listed. (D) Global view of KEGG enrichment pathways. 
A

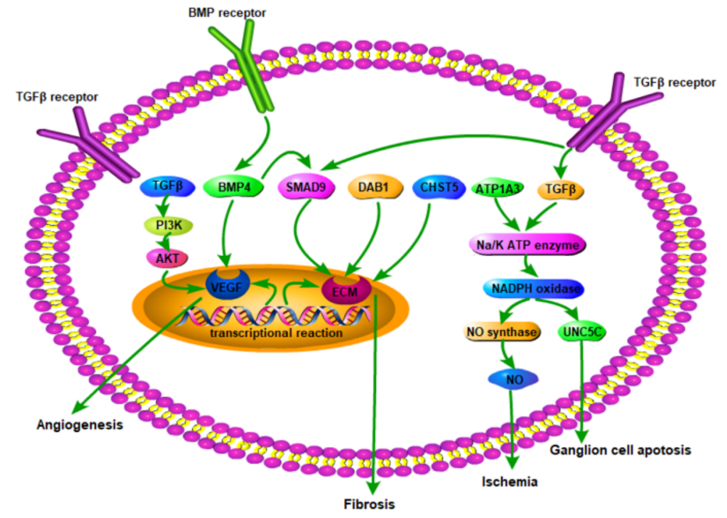

$\mathrm{C}$
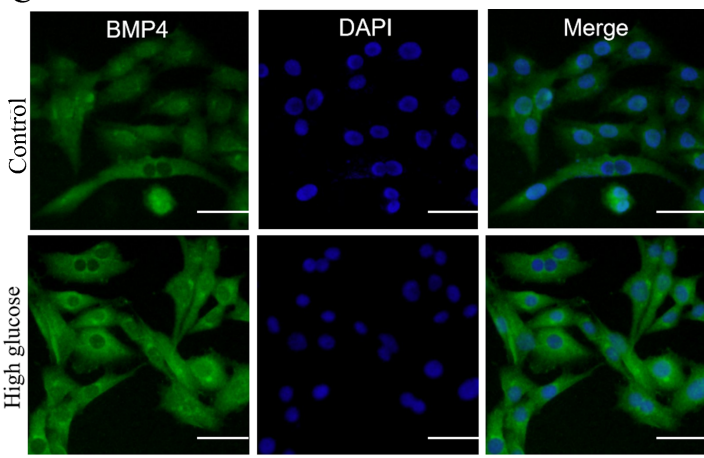

$\mathrm{D}$

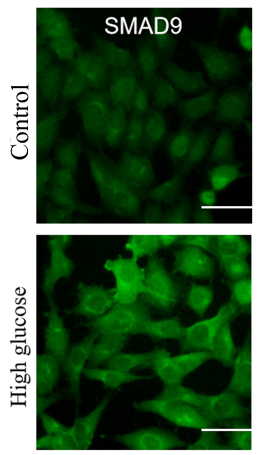

$\mathrm{G}$
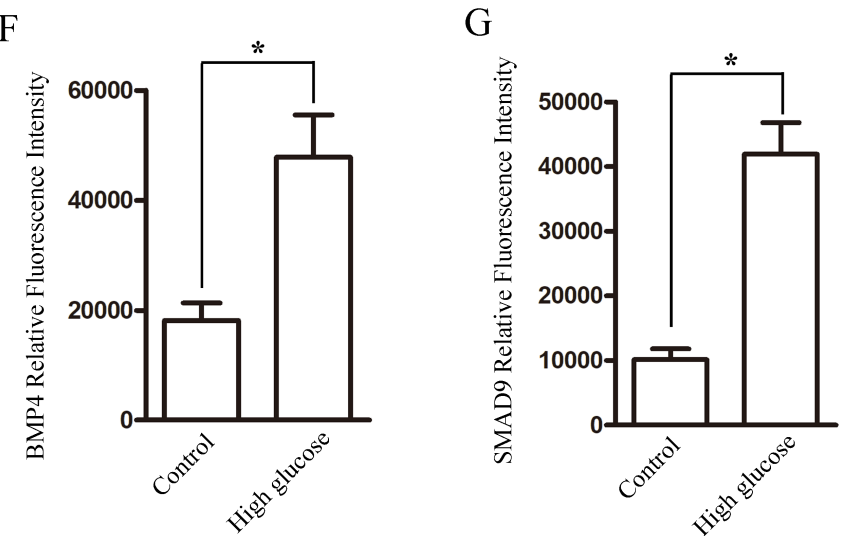

B

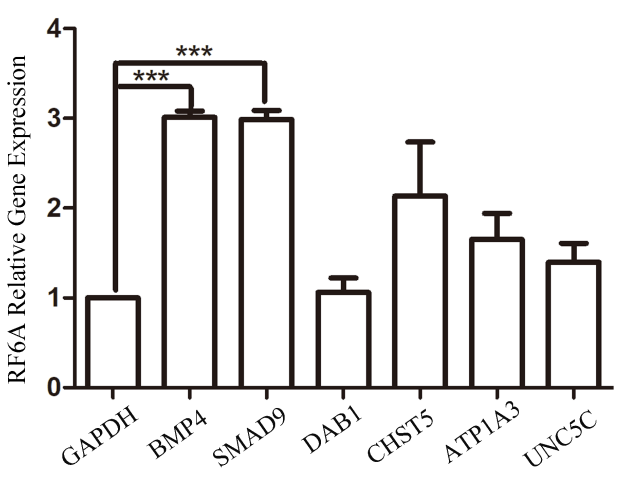

E
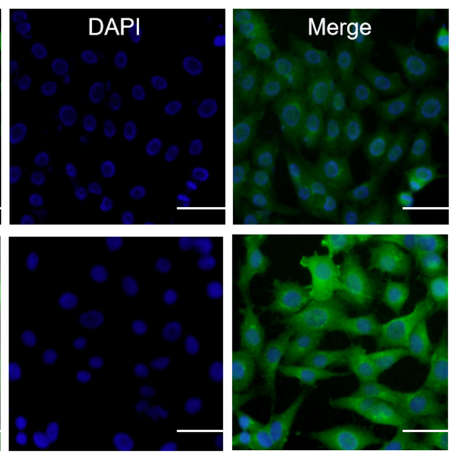

$\mathrm{H}$

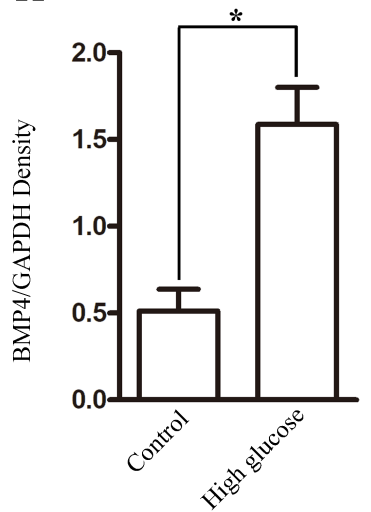

I

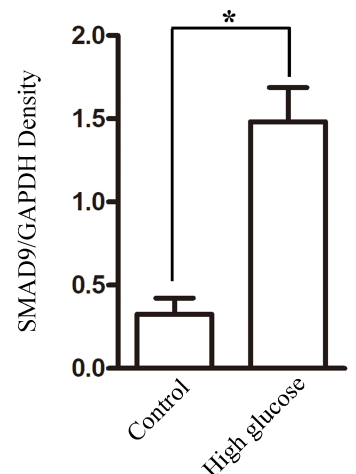

\section{Figure 2}

Validation of six differentially regulated genes in RF/6A cells. (A) Signaling pathway diagram of the six differentially regulated genes. (B) RT-qPCR validation of six differentially expressed genes in the highglucose-induced cell model. The fold change in expression indicated by RT-qPCR was determined by the relative Ct method and normalized to the expression of GAPDH. (C, D, F, G) Immunofluorescence results show BMP4 and SMAD9 expression after exposure to high glucose. The average fluorescence intensity of BMP4 and SMAD9 was much higher in the high-glucose group than in the normal group. $(E, H, I)$ The 
expression levels of the BMP4 and SMAD9 proteins were significantly higher in the high-glucose group, as detected by western blot. Scale bars: $50 \mu \mathrm{m}$. All values represent the mean \pm standard deviation. $\mathrm{n}=3$. ${ }^{*} \mathrm{P}<0.05,{ }^{* *} \mathrm{P}<0.01,{ }^{*} * \mathrm{P}<0.001$ compared with the control group.

A

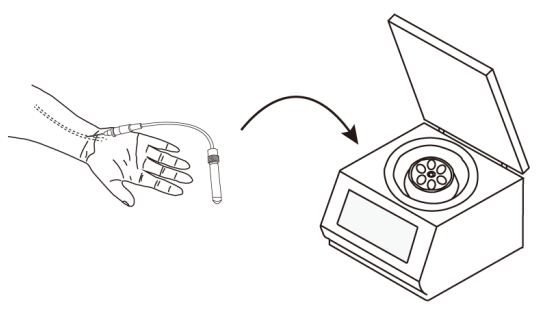

Collect sample

C
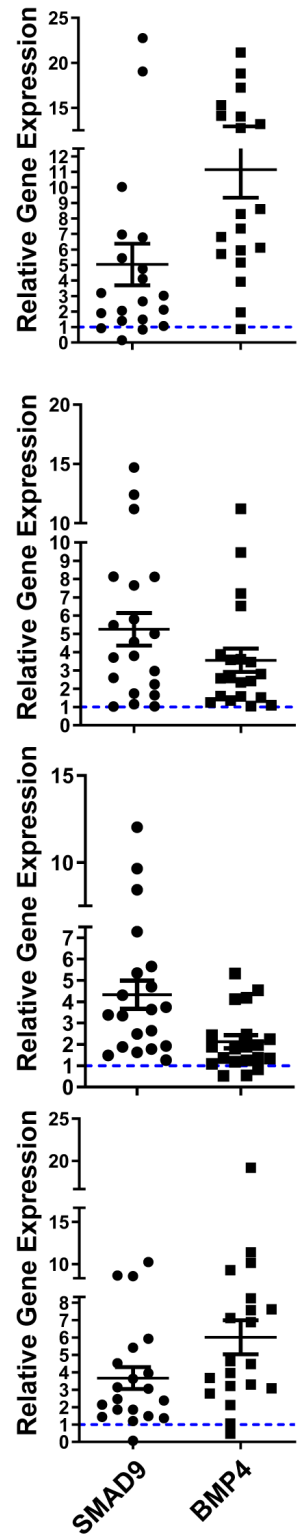
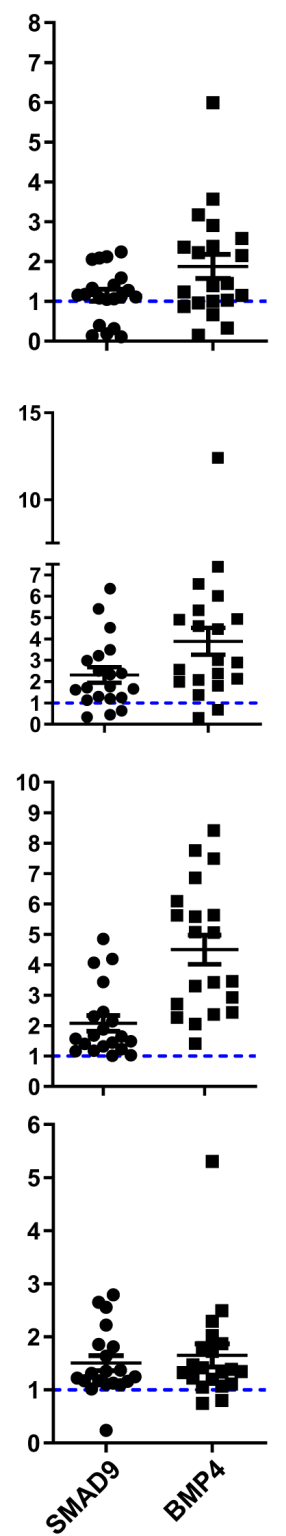

$\mathrm{B}$

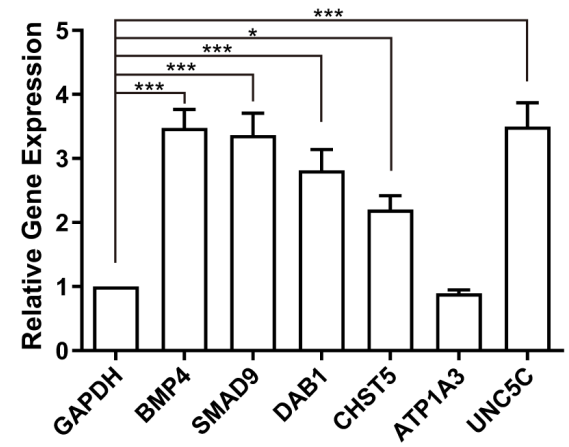

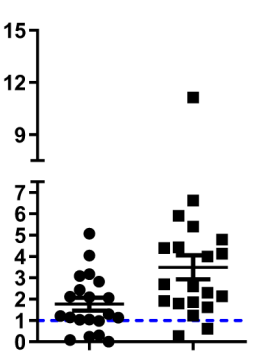
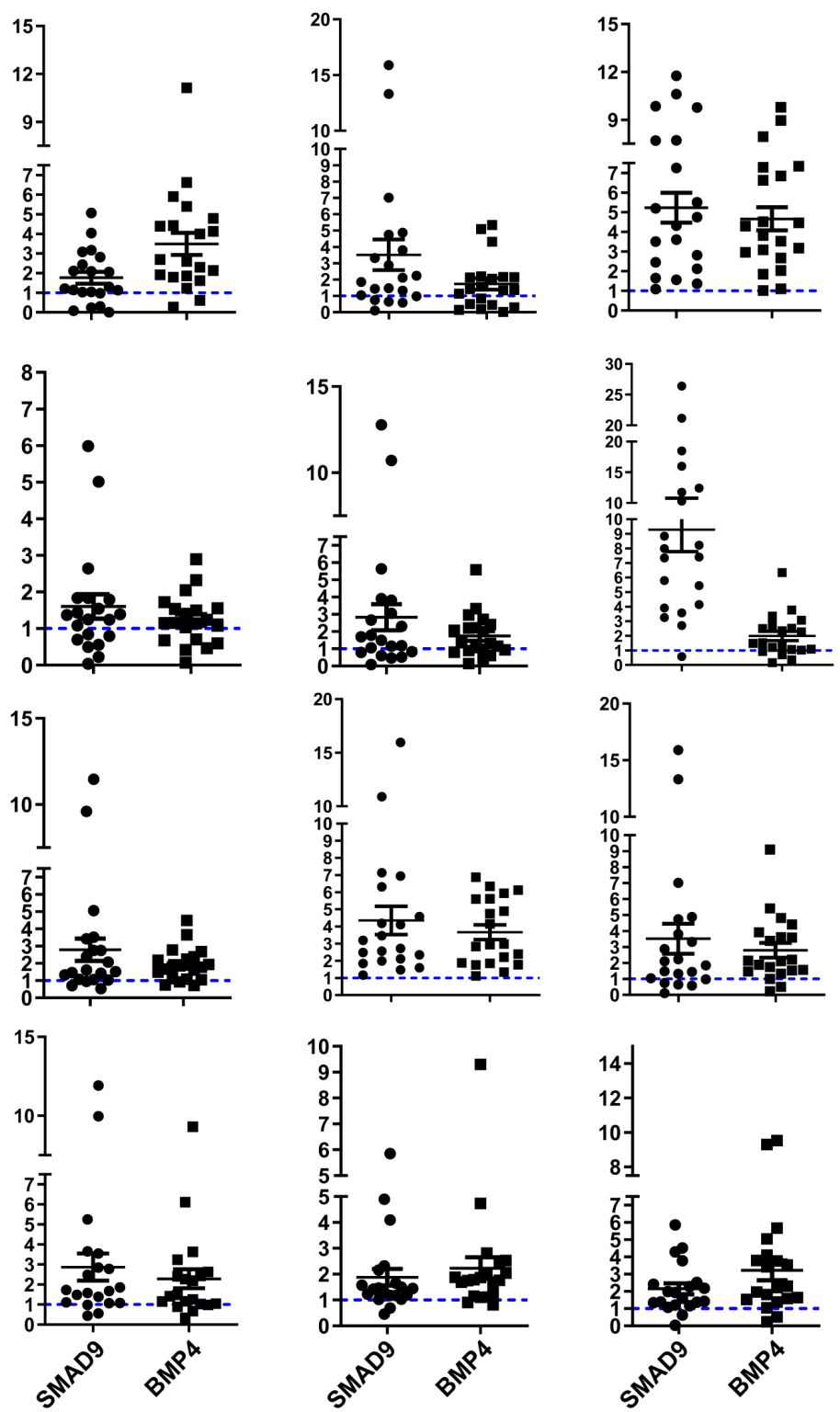

Figure 3

Validation of six differentially regulated genes in blood samples. $\triangle A \triangle S$ Samples were collected for PCR flow chart (B) RT-qPCR validation of six differentially expressed genes in DR blood samples. The fold change 
was determined by the relative Ct method and normalized to the expression of GAPDH. (C) RT-qPCR was used to analyze the expression of BMP4 and SMAD9 in each diabetic patient, and the blood samples of 20 healthy people were used as controls. (vs. GAPDH). All values represent the mean \pm standard deviation. $n=3 .{ }^{*} P<0.05,{ }^{*} \mathrm{P}<0.01,{ }^{*} * * \mathrm{P}<0.001$ compared with the control group.
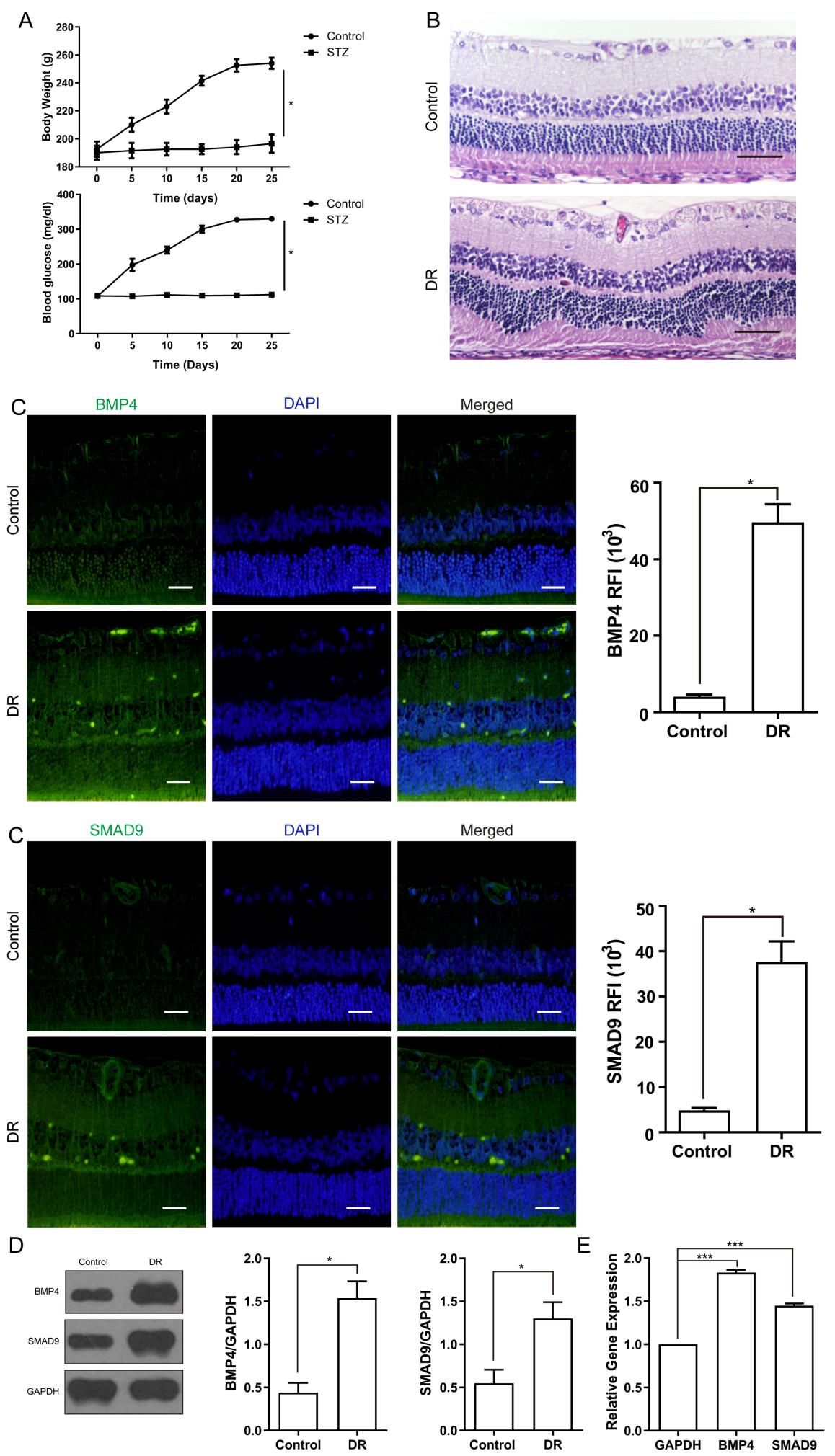

Figure 4 
Expression of BMP4 and SMAD9 in STZ-induced diabetic rats. (A) Body weight and blood glucose in rats at five, ten, fifty, twenty and twenty-five days after the injection of streptozotocin. (B) Morphological changes in diabetic rat retinas evaluated with HE staining at 12 weeks after STZ injection. (C) Detection of BMP4 expression by immunofluorescence. The expression of BMP4 was higher in STZ-induced diabetic rats than in control rats. SMAD9 expression in STZ-induced diabetic rats determined by immunofluorescence. The average fluorescence intensity of SMAD9 in the diabetic group was much higher than that in the normal group. (D, E) Detection of BMP4 and SMAD9 protein expression by western blot and PCR. GAPDH was used as a loading control. Scale bars: $50 \mu \mathrm{m}$. All values represent the mean \pm standard deviation. $n=3 .{ }^{*} P<0.05,{ }^{*} P<0.01,{ }^{\star \star *} P<0.001$ compared with the control group. 
A

BMP4
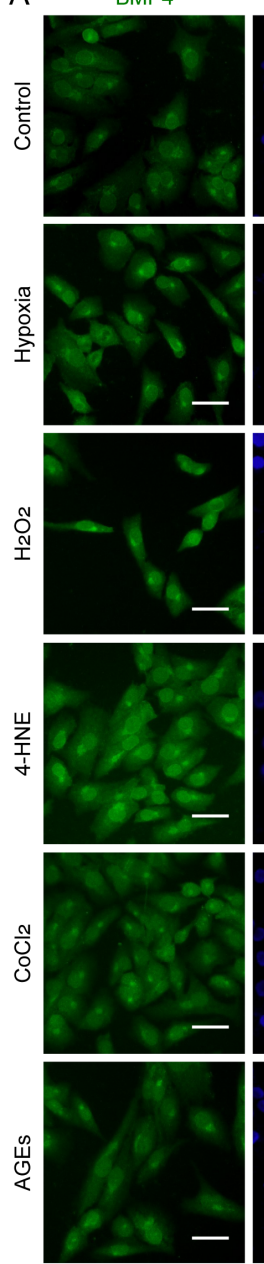

C

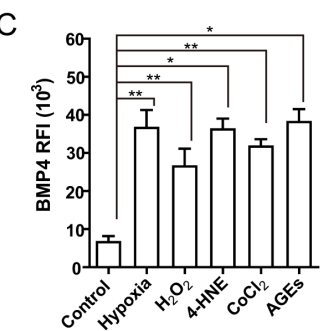

G

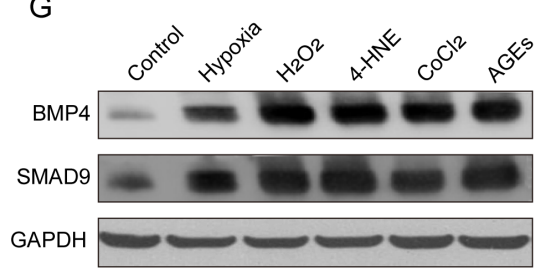

Merged
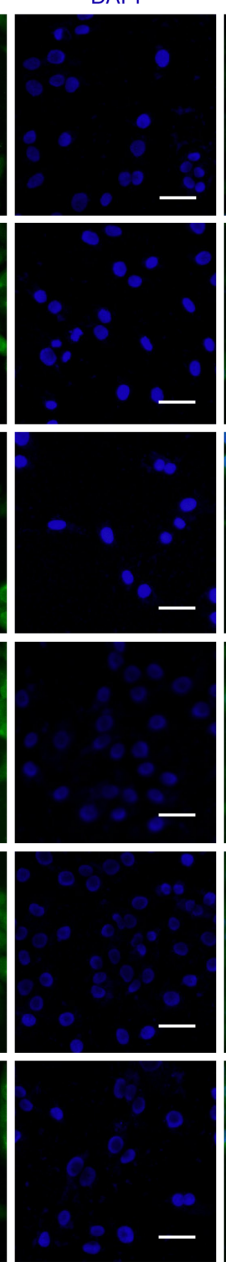

D

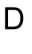

B SMAD9
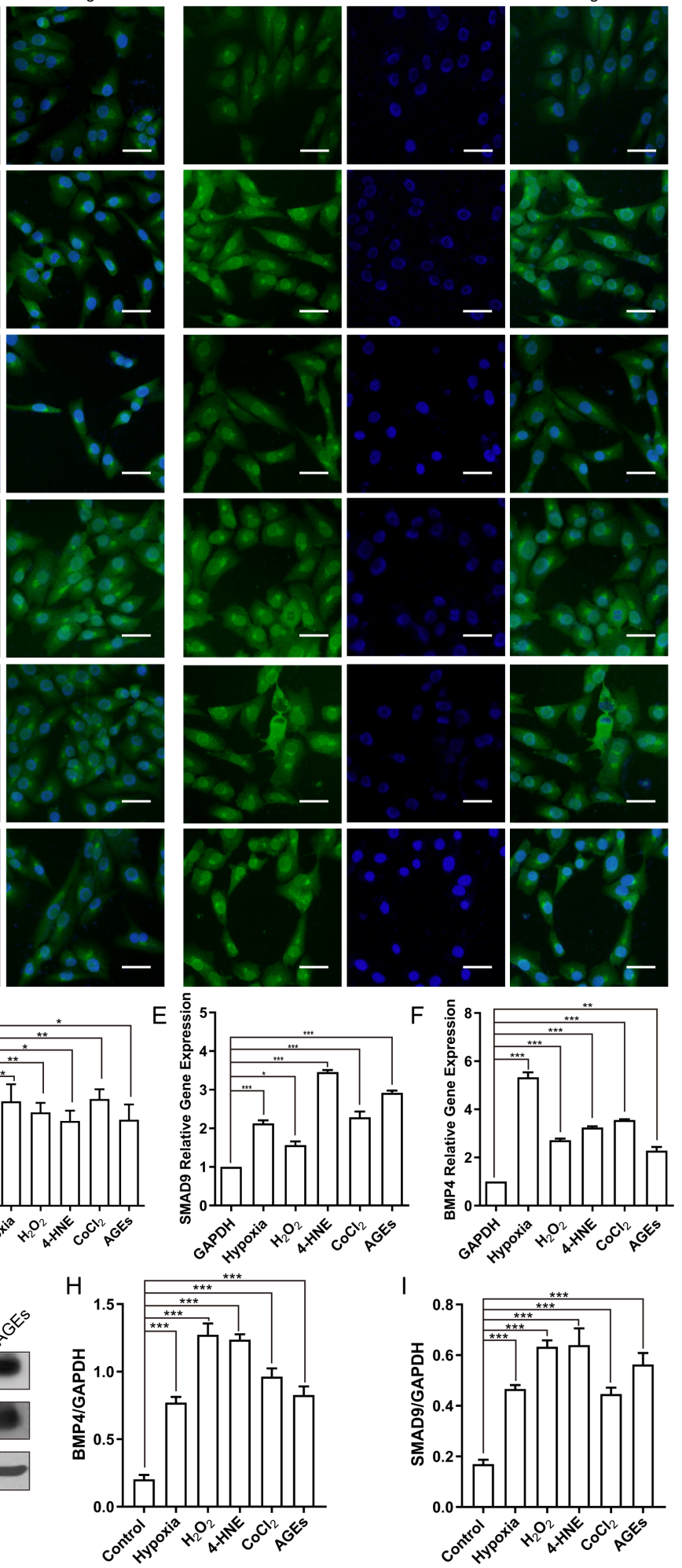

DAPI

Merged
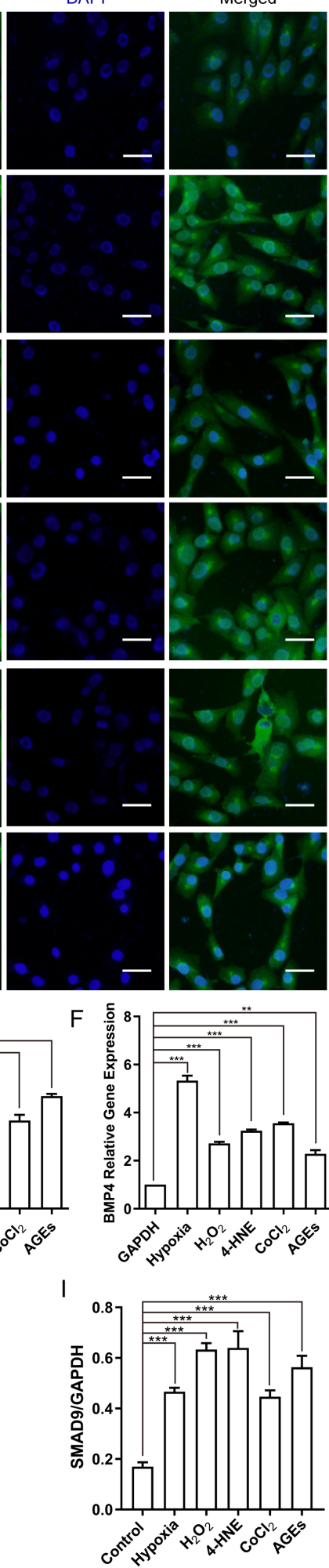

Figure 5

The expression of BMP4 and SMAD9 was verified in HRCEC models. (A, B, C, D) The expression of BMP4 and SMAD 9 detected by immunofluorescence. Scale bars: $50 \mu \mathrm{m}(\mathrm{E}, \mathrm{F}) \mathrm{BMP} 4$ and SMAD9 expression was detected in the DR HRCEC model by RT-qPCR. The expression of BMP4 and SMAD9 was significantly upregulated in these cell models compared to their expression in normal cells. $(G, H, I)$ The expression levels of the BMP4 and SMAD9 proteins were significantly higher in these five cell models, as detected by 
western blot. Scale bars: $50 \mu \mathrm{m}$. All values represent the mean \pm standard deviation. $n=3 .{ }^{*}<<0.05$, ${ }^{*} \mathrm{P}<0.01, * * * \mathrm{P}<0.001$ compared with the control group.

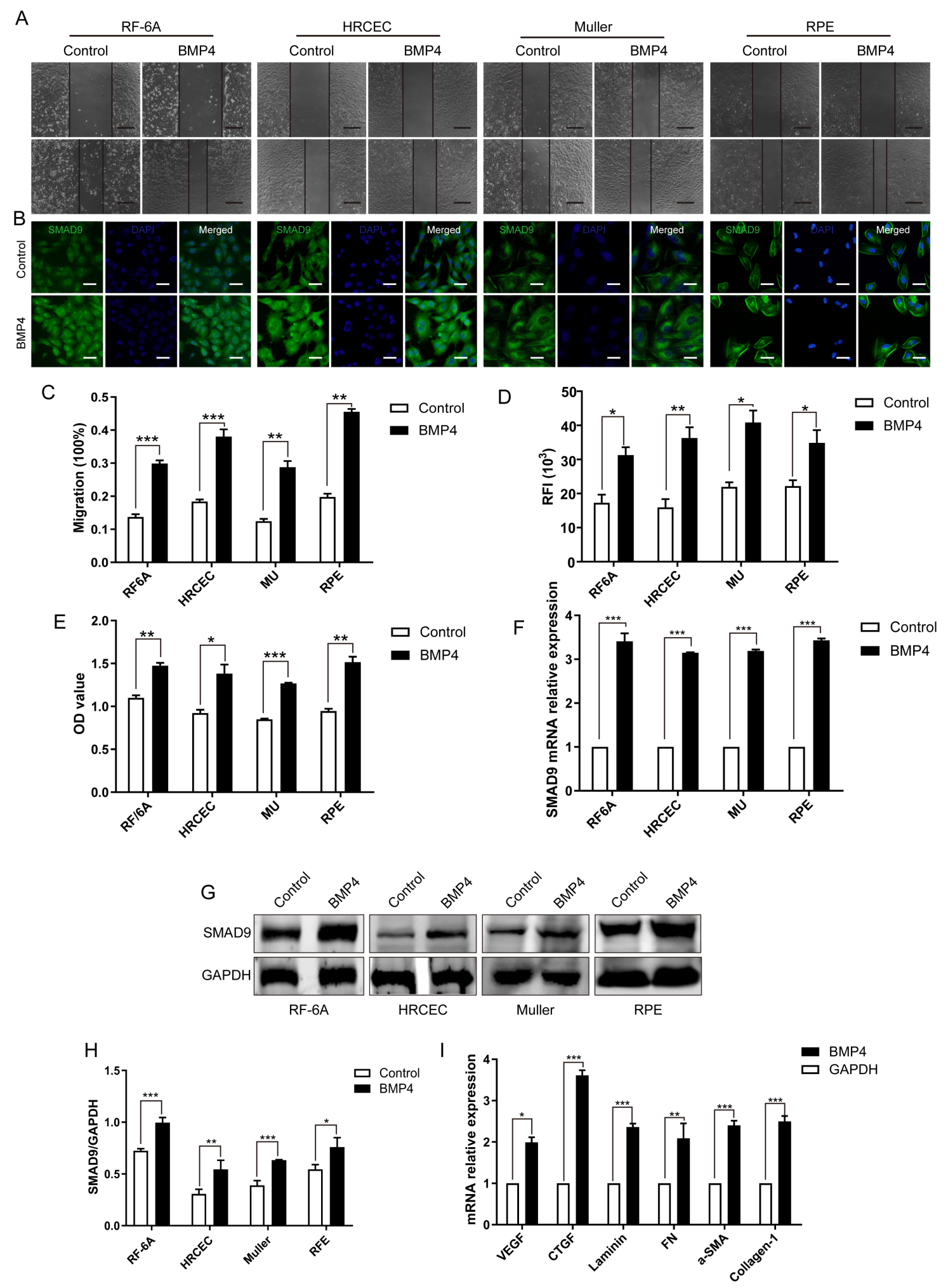

Figure 6

The function of BMP4 was validated in retinal cells. $(A, C)$ Wound scratch assays were performed to measure cell migration under BMP4 stimulation. Scale bars: $200 \mu \mathrm{m}(\mathrm{B}, \mathrm{D})$ Under BMP4 stimulation, SMAD9 expression in various cells was detected by immunofluorescence. (E) MTT assay was performed 
to assess cell proliferation under BMP4 stimulation. $(F, G, H)$ The expression of SMAD9 in various cells stimulated by BMP4 was detected by western blot and PCR. (I) The effect of BMP4 on the expression of VEGF and fibrosis-related factors in retinal vascular endothelial cells was detected by PCR. Scale bars: 50 $\mu \mathrm{m}$. All values represent the mean \pm standard deviation. $n=3$. ${ }^{*} P<0.05, * * P<0.01,{ }^{\star} * * P<0.001$ compared with the control group.

\section{Supplementary Files}

This is a list of supplementary files associated with this preprint. Click to download.

- Figs4.tif

- Figs6.tif

- FigS3.tif

- FigS7.tif

- Figs2.tif

- FigS1.tif

- SuppTable.docx

- Figs5.tif 